\title{
In-line, roll-to-roll morphology analysis of organic solar cell active layers
}

Rossander, Lea Hildebrandt; Dam, Henrik Friis; Carlé, Jon Eggert; Helgesen, Martin; Rajkovic, I.; Corazza, Michael; Krebs, Frederik C; Andreasen, Jens Wenzel

Published in:

Energy \& Environmental Science

Link to article, DOI:

10.1039/C7EE01900A

Publication date:

2017

Document Version

Peer reviewed version

Link back to DTU Orbit

Citation (APA):

Rossander, L. H., Dam, H. F., Carlé, J. E., Helgesen, M., Rajkovic, I., Corazza, M., Krebs, F. C., \& Andreasen, J. W. (2017). In-line, roll-to-roll morphology analysis of organic solar cell active layers. Energy \& Environmental Science, November(11), 2411-2419. https://doi.org/10.1039/C7EE01900A

\section{General rights}

Copyright and moral rights for the publications made accessible in the public portal are retained by the authors and/or other copyright owners and it is a condition of accessing publications that users recognise and abide by the legal requirements associated with these rights.

- Users may download and print one copy of any publication from the public portal for the purpose of private study or research.

- You may not further distribute the material or use it for any profit-making activity or commercial gain

- You may freely distribute the URL identifying the publication in the public portal 


\section{Accepted Manuscript}

This article can be cited before page numbers have been issued, to do this please use: L. H. Rossander, H. F. Dam, J. Carlé, M. Helgesen, I. Rajkovic, M. Corazza, F. C. Krebs and J. W. Andreasen, Energy Environ. Sci., 2017, DOI: 10.1039/C7EE01900A.

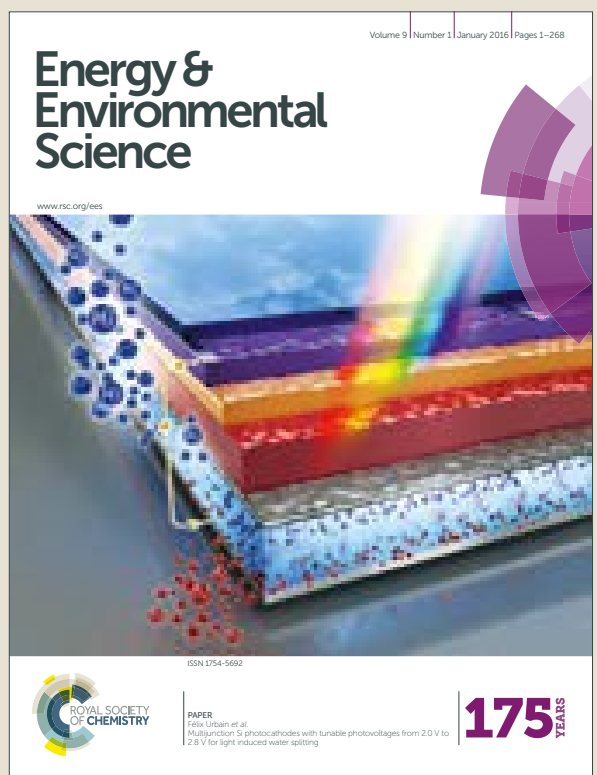

This is an Accepted Manuscript, which has been through the Royal Society of Chemistry peer review process and has been accepted for publication.

Accepted Manuscripts are published online shortly after acceptance, before technical editing, formatting and proof reading. Using this free service, authors can make their results available to the community, in citable form, before we publish the edited article. We will replace this Accepted Manuscript with the edited and formatted Advance Article as soon as it is available.

You can find more information about Accepted Manuscripts in the author guidelines.

Please note that technical editing may introduce minor changes to the text and/or graphics, which may alter content. The journal's standard Terms \& Conditions and the ethical guidelines, outlined in our author and reviewer resource centre, still apply. In no event shall the Royal Society of Chemistry be held responsible for any errors or omissions in this Accepted Manuscript or any consequences arising from the use of any information it contains. 


\title{
Journal Name
}

\section{ARTICLE}

\section{In-line, roll-to-roll morphology analysis of organic solar cell active layers}

Received 00th January 20xx, Accepted 00th January 20xx

DOI: $10.1039 / x 0 x \times 00000 x$

www.rsc.org/

\author{
L. H. Rossander ${ }^{a}$, H. F. Dam ${ }^{a}$, J. E. Carlé ${ }^{a}$, M. Helgesen ${ }^{a}$, I. Rajkovic ${ }^{b}$, M. Corazza ${ }^{a}$, F. C. Krebs ${ }^{a}$ and J. \\ W. Andreasen ${ }^{a} *$
}

We present the first comparative in situ small and wide angle X-ray scattering study of two polymers that are relevant for organic photovoltaics, during coating on a flexible substrate. From the obtained measurements we identified several differences between the drying of the two polymers. The polymer optimized for roll-to-roll coating attained its final morphological packing nearly instantly after deposition, and had the shortest drying profile. We therefore conclude that fast-drying polymers which are influenced less by drying temperature or substrate inhomogeneities are better suited for roll-to-roll coating, and that fundamentally, the kinetics of drying dominate the process in the case of roll-to-roll slot-die coating.

\section{Introduction}

The key requirement for organic solar cells to become widely implemented in society is that they must be adapted to large scale production. Due to cost and embodied energy, the only substrates fulfilling the requirements of production on such scales are flexible foils made from commodity polymers. Energy payback time (EPBT), the required operation time for a solar cell before it has generated the energy used for its production, was demonstrated to be as little as 10 days or less ${ }^{1}$. Unfortunately, it is commonly the case that an active layer polymer which may result in high efficiencies when spin coated on small area, rigid substrates, either results in much worse performance on flexible substrates, or completely fails to work at all. Beyond simple physical and chemical causes such as wetting problems during coating or solubility issues, the reasons behind this are unknown.

The main mechanism behind the functionality of organic solar cells is the bulk heterojunction ${ }^{2}$, which is dependent on phase separation between the donor polymer and acceptor (typically a fullerene derivative) on the order of $20 \mathrm{~nm}$. This fact, combined with typical packing distances of conjugated polymers of $0.4-1.5 \mathrm{~nm}$, implies that X-ray scattering is a well suited characterization technique for these materials. Additionally, it can be implemented in ambient atmosphere, which enables in situ characterization when combined with high time resolution and versatile sample environments.

\footnotetext{
a. Technical University of Denmark, Department of Energy Conversion and Storage, DK-4000 Roskilde, Denmark

b. Stanford Synchrotron Radiation Lightsource, Menlo Park, CA 94025-7015 USA Electronic Supplementary Information (ESI) available: [Calculations of total scanned volume, drying times, data reduction of X-ray scattering data, pictures and video of the experimental setup, DSC measurements and details of spin coated cell preparation]. See DOI: 10.1039/x0xx00000x
}

Many X-ray studies of polymers for photovoltaics have been performed on glass and silicon substrates ${ }^{3-5}$. In 2012 we demonstrated the first example of a study on flexible substrates similar to the ones used for large scale organic solar cell production ${ }^{6,7,8}$, and recently another in situ study of the classical benchmark polymer for organic solar cells, poly(3hexyl)thiophene (P3HT), coated on flexible substrate has appeared in the literature ${ }^{9}$.

The logical next step is to expand the experiments to include other polymers than P3HT. Therefore, this study includes a polymer based on 4,5-bis(2-hexyldecyloxy)benzo[2,1-b:3,4$b^{\prime}$ ']dithiophene (BDT) and dithienylthiazolo[5,4-d]thiazole (TTz) units, (PBDTTTz-4) to be compared with P3HT, both shown in Fig. 1. This polymer fulfils several considerations that influenced the choice of a complementary polymer to investigate - PBDTTTZ-4:PCBM was shown to result in more efficient solar cells when coated roll-to-roll (R2R) compared with $\mathrm{P} 3 \mathrm{HT}: \mathrm{PCBM}^{10}$, showed less degradation, and can also be produced using flow synthesis ${ }^{11}$, a requirement for production in large scale. These are parameters that were addressed and quantified as a relative merit factor in a large matrix screening study of 104 low band gap polymers identifying 13 polymers
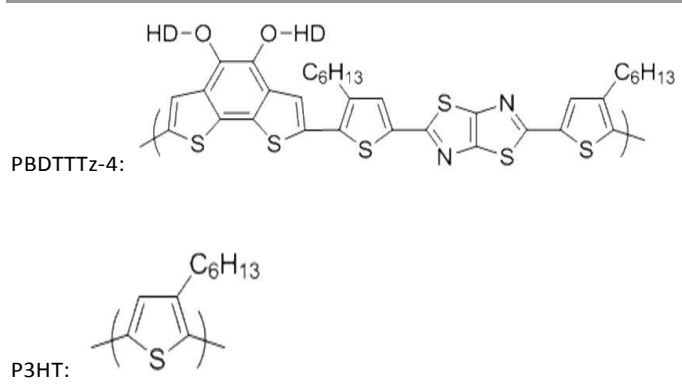

Figure 1 | The chemical structure of the polymer PBDTTTz-4 compared to P3HT. 
that outperforms P3HT for R2R coated large area solar cells ${ }^{12}$. In that study, it was demonstrated that large scale screening of donor-acceptor combinations with respect to the polymer performance in R2R coated solar cells can be effective in finding high-performing polymer backbone candidates. It was also shown, that further side-chain engineering may be necessary to optimize promising candidates for R2R coating, or even to enable coating of polymers that are failing completely in this setting. In the study presented here, we extend this approach with structural characterization in a realistic $R 2 R$ setting in order to identify further characteristics of polymers that may affect their performance under these conditions.

The typical performances obtained for the two polymers studied here, in spin coated and R2R coated devices respectively, are summarized in table 1 .

Table 1: Typical power conversion efficiencies in spin coated and R2R coated devices

\begin{tabular}{l|c|c|}
\multicolumn{2}{c}{ Spin coated } & R2R coated \\
\hline P3HT:PCBM & $3.8 \%^{\mathrm{a}}$ & $2.3 \%^{\mathrm{b}}$ \\
\hline PBDTTTZ-4:PCBM & $2.0 \%^{\mathrm{c}}$ & $3.0 \%^{\mathrm{d}}$ \\
\hline
\end{tabular}

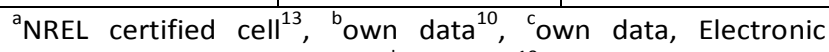
Supplementary Information, ${ }^{\mathrm{d}}$ own data ${ }^{10}$

The reasons why PBDTTTz-4 behaves better in R2R coating are probably many, so several experiments at different solid concentrations were included here because the concentration of solids was previously shown to influence the morphology formation $^{6}$. By using several concentrations, we get insights into the more elementary behaviour of the polymers, which can then be compared to other studies where rigid substrates were used. Moreover, the included variations in concentration shows how this technique gives detailed insight into the fundamental drying dynamics of the polymer:fullerene mixtures investigated, enabled by the high time resolution, high flux and careful control of the film thickness.

\section{Results and discussion}

In situ measurements covering a large processing parameter space

Assuming the bulk heterojunction morphology is a determining factor for solar cell efficiency, we study the structure development under conditions as close as possible to actual large scale coating conditions. We based the experiments on coating parameters taken from previous process optimizations which maximized the solar cell performance ${ }^{14,10}$. Using heating plates (see overview sketch in Fig. 2), the coating temperature was individually controlled for each polymer, to be $60^{\circ} \mathrm{C}$ and

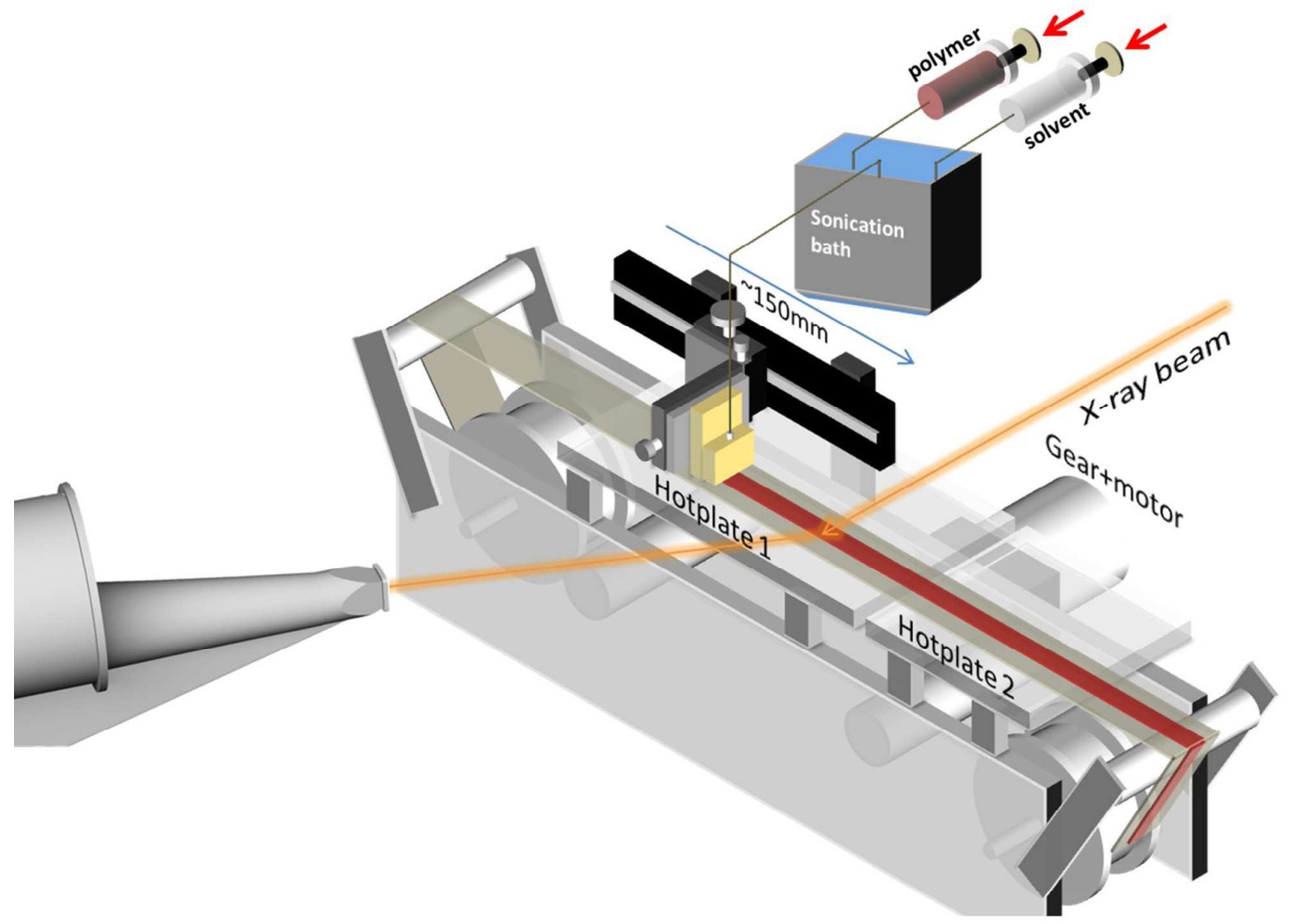

Figure 2 | Sketch showing the micro roll-to-roll coating setup integrated with X-ray scattering at a synchrotron. Polymer stock solution and solvent is supplied by differential pumping, shown at top right. The solutions are mixed in a tee, kept in a sonication bath and fed to the coater head which can be moved automatically along the web direction, to provide a continous change in drying time, all the while the coated film is exposed to X-rays that are scattered and collected at the end of the flight tube, sketched to the left. 
$90^{\circ} \mathrm{C}$ for $\mathrm{P} 3 \mathrm{HT}$ and PBDTTTz-4, respectively. The higher temperature needed for PBDTTTz-4 is required because of its higher viscosity, which is presumably caused by agglomeration in solution ${ }^{10}$. The more viscous solution is favourable for $\mathrm{R} 2 \mathrm{R}$ coating because it makes the coated film more resistant to mechanical disturbances such as movement of the substrate. The dry thickness of the polymer:fullerene films has to be much thicker $(480 \mathrm{~nm})$ than usually used in morphology studies as this reflects practical use of the polymers.

In a previous study ${ }^{6}$ we found that morphology is influenced by solution concentration, so to investigate this effect in greater detail, we designed the experiments to include a large parameter space by changing concentration as well as dry film thickness. This was accomplished by controlling pumping rate of stock solution and solvent in parallel, thereby achieving changing concentrations. We performed two separate experiments with the same concentration gradient. One set of measurements had constant dry thickness by increasing the total pumping rate while decreasing concentration. The other had a constant total pumping rate and a decreasing dry thickness through a decrease of concentration.

Constant tension is needed to keep the film aligned, and we included a custom braking arrangement in the setup to achieve this. Some fluctuations that could not be fully eliminated were observed in almost all the measurements due to tension based alignment variations. The effect is stronger for higher concentration experiments, which is caused by the greater layer thickness in those experiments where a change in incoming angle has a larger impact on the scattered intensity. Another challenge of the in situ measurements is variation in substrate wetting and slight changes in coated width due to this. The varying width also affects the integrated intensity, explaining some of the observed fluctuations.

The advantages outweigh the limitations even with the added challenges, because in situ measurements improve result statistics as well as reduces (or eliminates) beam damage. No part of the coated polymer film is subjected to radiation for more than the time it takes for it to move through the beam, and the moving sample allows us to scan a total solution volume of $1625 \mathrm{~mm}^{3}$, a larger volume of sample than would usually be feasible in batch experiments. After correcting for readout time, we achieved 656 measurements during a drying time of 21 seconds, defined by the relative speed of the foil and the coater head, which gives a time resolution of 31 measurements per second of drying time, 3 times more than the $10 \mathrm{~Hz}$ framerate of the detector. Finally, this type of study is closer to conditions in actual large scale organic solar cell production, thus simulating realistic drying conditions for actual devices.

\section{Polymer Drying Dynamics}

The experiment described above, allows us to measure directly how the coating process affects the morphology of the two polymers. With two different polymers - P3HT which has been thoroughly studied ${ }^{3}$ and PBDTTTz-4 which performs better than P3HT when R2R coated, but which has yet to be subjected to in-depth morphology studies - we are able to investigate morphological differences between the two polymers as a function of processing parameters in an R2R setting. In the following discussion, we highlight the differences found, and go on to describe them and why they may lead to better R2R performance.

Even though PBDTTTz-4 results in better solar cell performance when roll-to-roll-coated, Fig. 3 shows that it is significantly less crystalline than P3HT. The solar cell performance of PBDTTTz-4 therefore appears to depend less
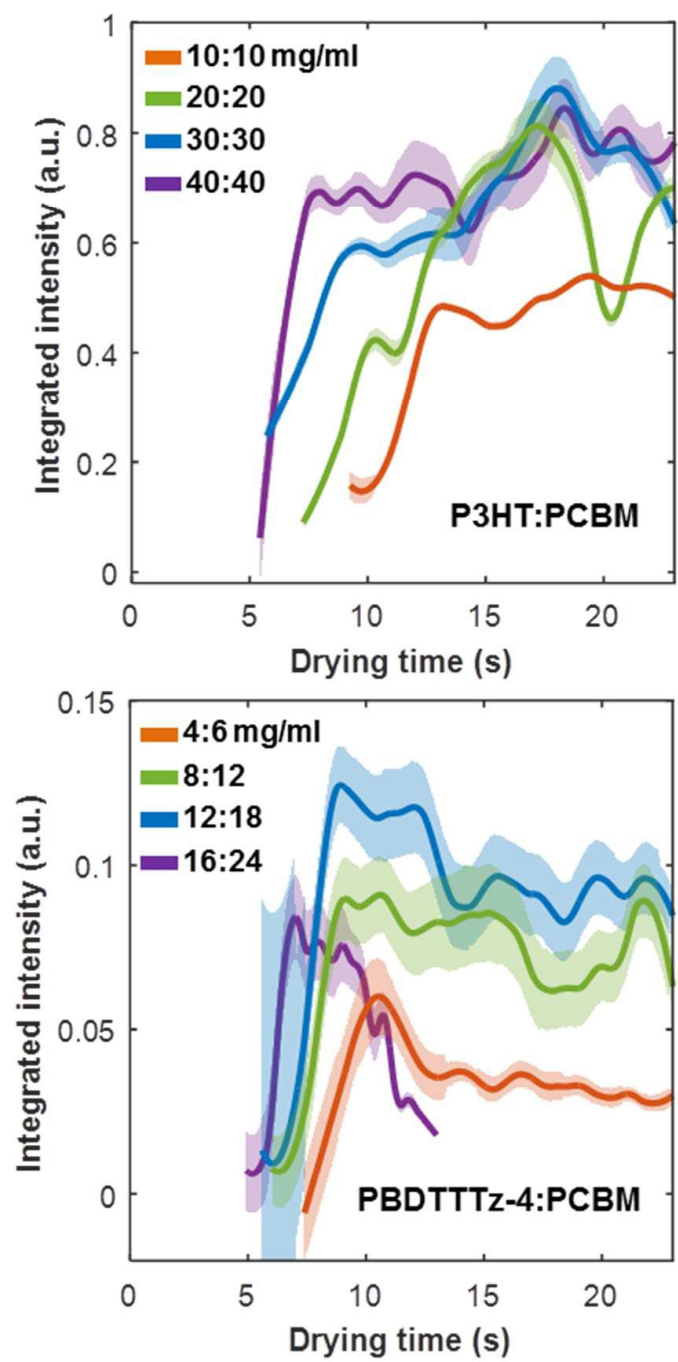

Figure 3 | Plot showing the development of integrated intensity in the 100 lamellar structure peak for top: $\mathrm{P} 3 \mathrm{HT}: \mathrm{PCBM}$ and bottom: PBDTTTz-4:PCBM. The first point of each curve represents the time when the polymer has crystallized enough to form a structure peak, referred to as the crystallization onset. Concentrations for Р3НТ: $\mathrm{PCBM:} \mathrm{purple}=40: 40$, blue=30:30, green=20:20, orange $=10: 10$ for P3HT:PCBM. Concentrations for PBDTTTZ-4:PCBM: purple $=16: 24 \mathrm{mg} / \mathrm{ml}$, blue $=12: 18 \mathrm{mg} / \mathrm{ml}$, green $=8: 12 \mathrm{mg} / \mathrm{ml}$, orange $=4: 6 \mathrm{mg} / \mathrm{ml}$ PBDTTTZ-4:PCBM. The 16:24 PBDTTTz-4:PCBM measurement shows an example of a failed coat ending abruptly at $13.5 \mathrm{~s}$ drying time where the video in the Electronic Supplementary Information (filename:pcdtttz4P3HT_parallel.mov) clearly shows the solution failing to wet the substrate. The colour-matched areas represent a calculated running standard deviation, and the line the corresponding running average. 
on crystallinity in contrast to $\mathrm{P} 3 \mathrm{HT}$. The points at which the curves in Fig. 3 begin are defined by the point where the polymer structure peak is strong enough for the fitting algorithm to fit a peak. We choose to call this point the crystallization onset, and this expression will be used henceforth. For PBDTTTz-4, the crystallization onset is less affected by concentration than it is for P3HT. This leads us to conclude that local variations in concentration, possibly caused by the moving and flexible substrate, affect the crystallization of PBDTTTz-4 less than P3HT. A polymer which dries faster, while still forming crystallites of about $60 \mathrm{~nm}$ and having a packing distance of about $20 \AA$, also appears to be favourable for roll-to-roll coating. This is seen from the steeper drying profiles of PBDTTTz-4 in Fig. 3. Both polymers also have a slight dependence of integrated intensity on concentration, which is explained by the changing dry thickness, but the integrated intensity overall is surprisingly constant for the experiments with changing dry thickness, which seems to indicate that a
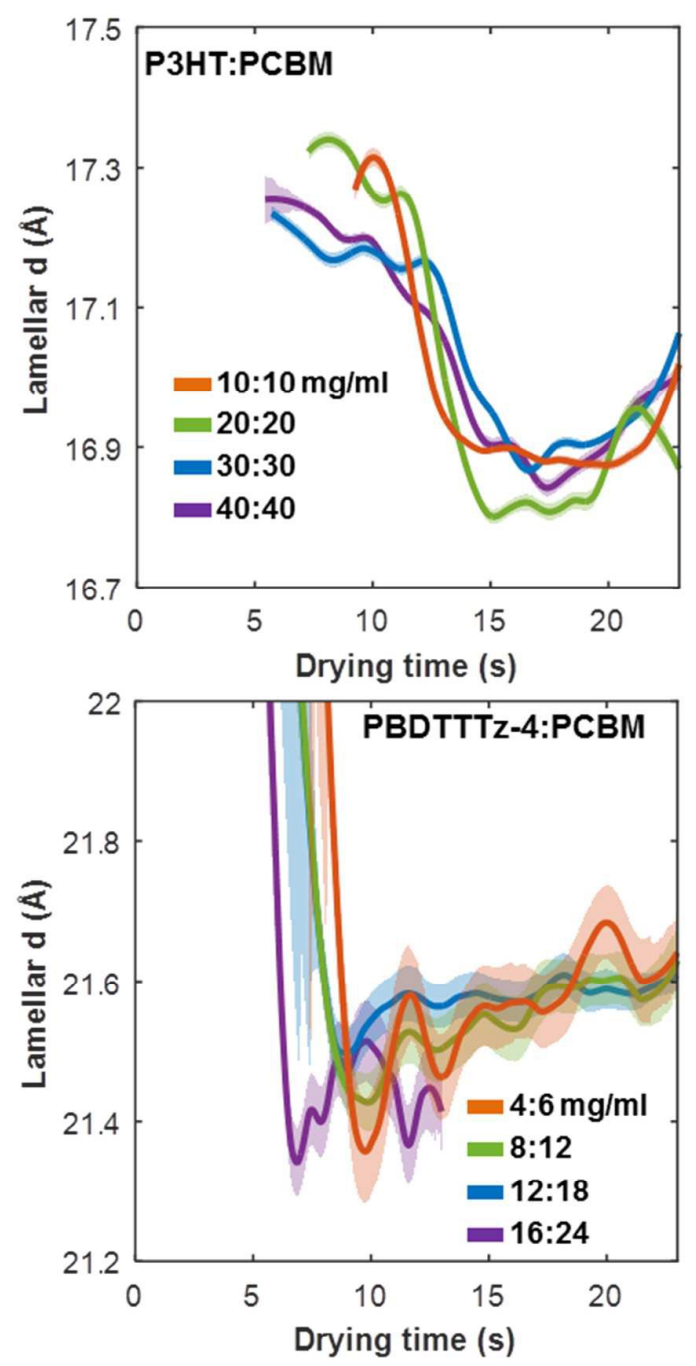

Figure 4 | Plot showing the development of lamellar spacing for top: Р3HT:PCBM and bottom: PBDTTTz-4:PCBM. Concentrations and legend the same as Fig. 3. thicker layer results in a more amorphous polymer layer.

Conclusions drawn from the integrated, diffracted intensity should be made carefully, as the width of the coated film and variations in thickness will cause a change in diffracted intensity which is unrelated to polymer crystallinity. As mentioned above, a few measurements were influenced by failed coating or changes in coating width, illustrated by videos showing the coating alongside the measured scattering in the Electronic Supplementary Information. Even when taking this into account though, considering the large number of measurements in one experiment and the comparable background integrated intensities across all experiments (ESI figures 8 and 9) the relative integrated intensities are convincing for comparing crystallinity within the frame of this study.

From these observations, it would appear that wettability and higher viscosity of the solution may be more important for R2R coated solar cell performance than the degree of crystallinity of the polymer. This may seem at odds with earlier work, as for instance recently published results by Moseguí González et al. ${ }^{15}$, where a clear correlation between polymer crystallinity and solar cell performance was presented. However, this study only considered $\mathrm{P} 3 \mathrm{HT}$ on glass, and the disagreement therefore illustrates the need to investigate different kinds of polymers, especially those determined to perform better in R2R coating, to achieve a complete understanding of the conditions leading to optimized solar cell performance. An interesting addition to the measurements presented here would be an absolute determination of crystallinity, in lieu of the study by Moseguí González et al. ${ }^{15}$, but this is impossible to perform in situ with the current setup, and is instead considered for future studies.

Fig. 4 shows the development of packing distance with drying time, and contrary to $\mathrm{P} 3 \mathrm{HT}$, we observe no change in packing distance of PBDTTTz-4 during drying, neither from neat solution (ESI fig. 4) nor in blends with PCBM. In contrast, we confirm a slight decrease in lamellar spacing with drying for $\mathrm{P} 3 \mathrm{HT}$, less pronounced in the constant dry thickness experiments (ESI Fig. 5) where it does not attain the same lamellar packing distance within the time frame of the measurements. The constant dry thickness experiment has much more solvent and although the delayed evaporation certainly impacts the kinetics of the blend during drying, the exact process that leads to larger packing distances cannot be determined from our results.

In conjunction with a slight increase in crystallite sizes for the mixture containing PCBM (Fig. 5) compared to pure P3HT (ESI Fig. 2), the d-spacing also increases when PCBM is added as observed before ${ }^{4}$. The same effect is seen for PBDTTTz4:PCBM in Fig. 4 (and for pure PBDTTTz-4 (ESI Fig. 4), although it attains the final $d$-spacing immediately, instead of after the period of stabilization seen for P3HT. Furthermore, a small difference is observed for crystallite sizes between neat PBDTTTz-4 and PBDTTTz-4:PCBM, in contrast to the differences observed for neat $\mathrm{P} 3 \mathrm{HT}$ and $\mathrm{P} 3 \mathrm{HT}$ in blend with PCBM. The crystallite size of PBDTTTz-4 is larger than for the 
P3HT blends, corresponding well with the higher viscosity and agglomeration in solution.

The crystallization onset apparently depends more on polymer kinetics than on the presence of solvent, illustrated by the plot in Fig. 6 showing summed counts outside the polymer peak which corresponds to X-rays scattered mainly from the polyethylene terephthalate (PET) substrate. The substrate scattering seen outside the polymer structure peak depends on the penetration of the X-ray beam through the top layer, and is therefore an indirect measurement of the solvent content in the film. It shows that for $\mathrm{P} 3 \mathrm{HT}$, the solvent evaporates with the same rate for all concentrations, even though the crystallization onset seen from the integrated intensity curves in Fig. 3 for the polymer peaks clearly depends on the concentration. This is explained by a shorter separation of individual polymer chains in the higher concentrated solutions, making it more energetically favourable to form ordered complexes.
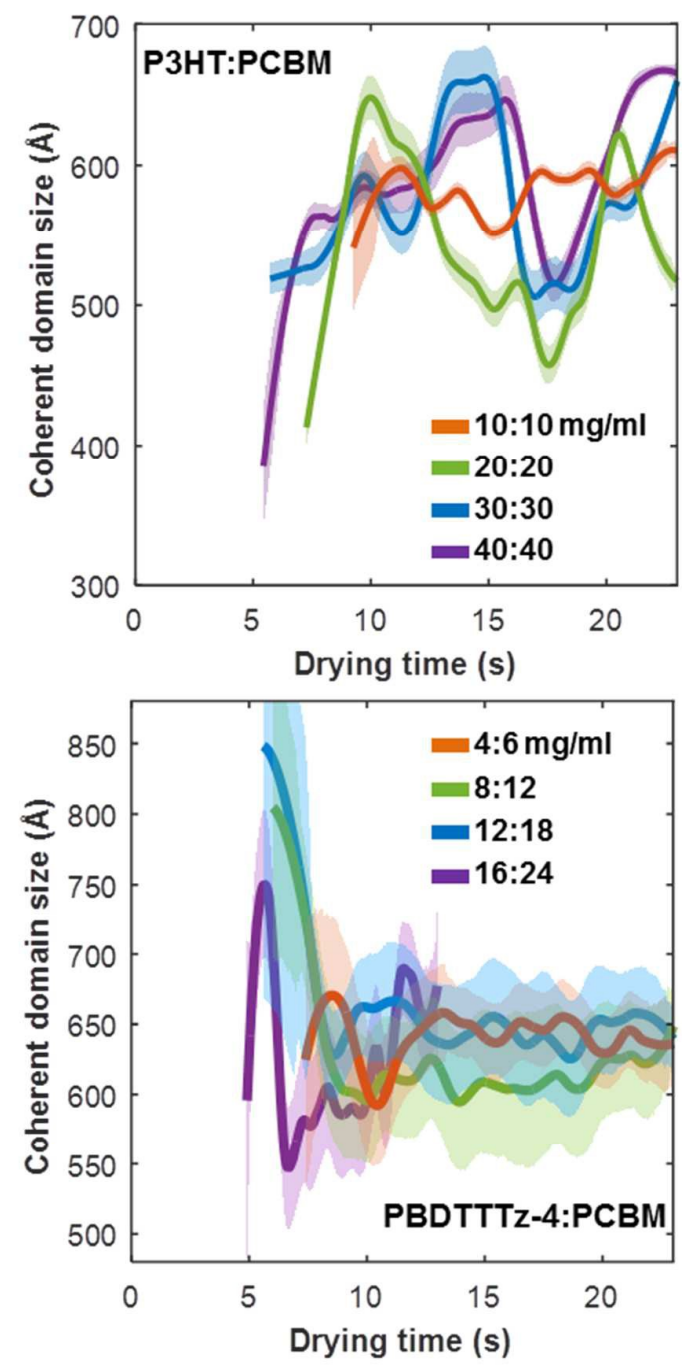

Figure 5 | Plot showing the development of crystallite size for (a) P3HT:PCBM and (b) PBDTTTz-4:PCBM(right). Concentrations and legend the same as Fig. 3.
After about 3 seconds we see a brief reduction in intensity in the curves showing integrated background intensity during the P3HT experiments (top and middle in Fig. 6). The feature is consistent throughout nearly all experiments indicating that it is a general effect of the technique. It is independent of concentration and presence of polymer, as even the pure solvent measurements shows the same feature. The dip coincides with the length and shape of the drying front, and the solvent evaporation curves also show that it gradually lengthens as the wet thickness of the film increases. A corresponding dip lacks in the curves for integrated intensity in the polymer peaks in Fig. 3, leading us to conclude that this is an effect of the drying front and that it has limited influence on the crystallization of the polymer.

The exact physical nature of PBDTTTz-4 ordering in solution, which we infer from the high viscosity and near-instant crystallization on the substrate, cannot be determined from the scattering data alone. It has been shown that conjugated polymers may exhibit various types of liquid crystalline behaviour including temperature dependent (thermotropic) ${ }^{16}$ and lyotropic liquid crystallinity (LLC), which depend on both temperature and concentration in solution ${ }^{17}$. Kleinheinz et al. showed that the LLC behaviour of $\mathrm{P} 3 \mathrm{HT}$ in solution causes time dependent ordering in the liquid phase ${ }^{18}$. To get an indication of whether PBDTTTZ-4 has a similar or even more pronounced propensity to form ordered structures or actual mesophases in solution we applied differential scanning calorimetry (DSC) to the polymer solid materials. Whereas $\mathrm{P} 3 \mathrm{HT}$ exhibits a clear melting and crystallization peak, this is not the case for PBDTTTZ-4 (ESI, figure 15). It is thus tempting to infer that the ordering observed in the solid films of PBDTTTz-4 is an actual mesophase as opposed to the (semi)crystalline nature of $\mathrm{P} 3 \mathrm{HT}$. The reason for the difference in the behaviour of the polymers may lie with the much stiffer backbone of PBDTTTz-4 caused by fused thiophenes.

To determine the actual liquid crystalline phase behaviour of PBDTTTz-4 in solution will require studies with polarized optical microscopy ${ }^{18,19}$ which is beyond the scope of the current study.

\section{Outlook}

The significantly different behaviour of PBDTTTz-4 in solution, during casting and in the solid film, as compared to P3HT, merits further studies of how ordering and potential formation of mesophases in solution may be affected by concentration and coating methods. Particularly, it appears attractive to investigate the use of micro-structured guides in the coating equipment for flow or shear induced nucleation and crystallization as described by Qu et al. ${ }^{20}$, provided that the kinetics allow such applications at high coating speeds of several meters per minute. 
explains the variations in the integrated intensity seen for nearly all measurements. Monitoring the reflected beam and Yoneda ${ }^{21}$ peak positions in the GISAXS measurements (ESI Fig. 11), could be used as a real time indicator of the effective incident angle. In future experiments this can be used in combination with high quality video feeds to precisely track the width of the coated film, thus providing a statistical volume correction to be applied as integrated intensity normalization, thereby improving the analysis of the GIWAXS data when both GIWAXS and GISAXS are performed simultaneously. The effects of foil movements may also be alleviated with a more tensioned substrate and therefore less variation in coated width. Such additions are being developed,

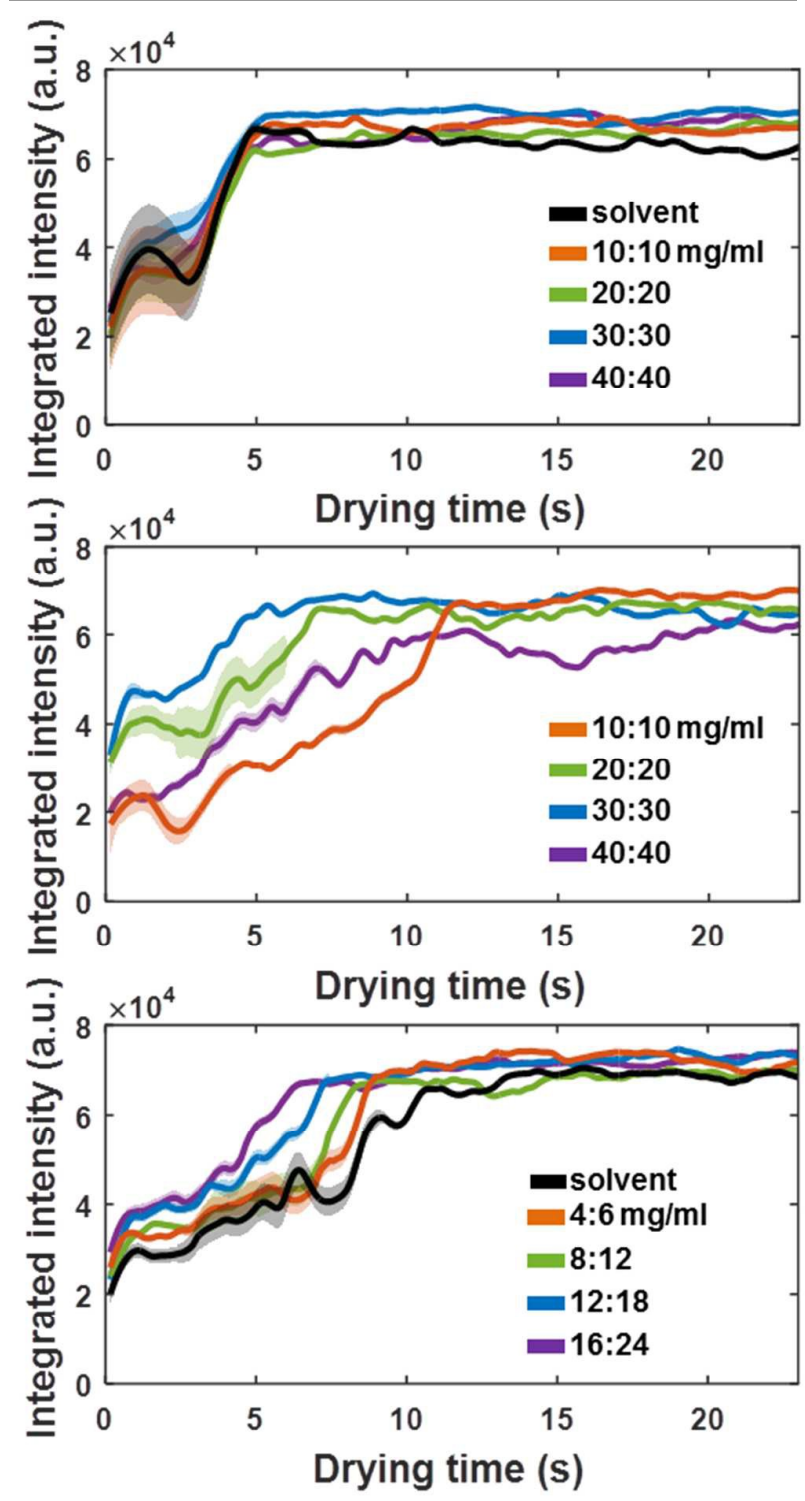

Figure 6 | Plots showing the integrated counts in the PET region( $q=0.4-3)$ as a function of drying time for top: Р3НТ:РСВM, middle: РЗНТ:РСВM with constant dry thickness and bottom: PBDTTTz-4:PCBM. The concentrations shown as in legend. and with more advanced in situ capabilities at several beamlines (i.e. 7.3.3 at the Advanced Light Source, cSAXS at the Swiss Light Source and BL26B at the European Synchrotron Radiation Facility) simultaneous SAXS and WAXS will also become an option for future experiments.

Combining simultaneous measurements of both wide and small angle scattering with high quality video feeds, can unlock the full potential of in situ experiments. The in situ setup has several impacts on the data quality, which could be alleviated to increase the statistical significance of the measurements. Foil movement influences the measured intensity, which together with multiple scattering effects (ESI Fig. 7)

\section{Experimental}

\section{In situ R2R coating}

We describe here the first synchrotron measurements of polymer solar cell coating using the setup reported previously ${ }^{22}$ We based the setup design directly on the actual coating machines developed by Krebs et al. $^{23}$ for $\mathrm{R} 2 \mathrm{R}$ production of organic solar cells. The main changes implemented for the machine used here was to reduce the width of the substrate foil to minimize air scattering and the introduction of a brake to improve the stability of the web. Remote control of syringe pumps and slot die coating head was also required to perform coating remotely during exposure to the $\mathrm{X}$-ray beam. This also required several cameras to enable the controllers to see the coating quality from outside the experiment hutch at the synchrotron. Images and videos of the setup during measurement are included in the Electronic Supplementary Information.

We designed the experiment to include and compare a wide parameter space by changing concentration as well as film dry thickness. This was accomplished using two programmed syringe pumps (nemESYS from Cetoni), that were controlled to change pumping rate in parallel and thereby achieve changing concentrations. The syringe pump containing polymer solution is controlled by one syringe pump (pump 1), the other (pump 2) controls a syringe with pure solvent. For each solution to be investigated, pump 1 is initially pumped by itself, resulting in a film of maximum concentration. Next, pump 2 is set to $25 \%$ of pump 1 , while pump 1 is reduced to $75 \%$ of its original rate. This way the mixture reaching the coater head is effectively a 1:4 dilution of the original mixture. This dilution is then carried out 4 times, and each experiment thereby comprises a set of 4 concentrations, after which pure solvent is pumped through to cleanse tubes and coater head before doing the next measurement. The stock solutions were of the concentrations $40: 40 \mathrm{mg} / \mathrm{ml}$ P3HT:PCBM and 16:24 mg/ml PBDTTTz-4:PCBM and were prepared immediately before the experiments, which lasted less than an 1 hour each. The 3 dilutions resulted in a total of 4 concentrations for each solution: 40:40, 30:30, 20:20 and $10: 10 \mathrm{mg} / \mathrm{ml}$ for the P3HT mixtures and 16:24, 12:18, 8:12 
and $4: 6 \mathrm{mg} / \mathrm{ml}$ for PBDTTTz-4. Measurements were also performed on the pure polymers with the same concentrations. The solvent and solution from the two pumps were combined in a mixing- $T$ part kept inside a heated ultrasonic bath to ensure smooth mixing. Before changing to the second polymer a complete manual cleaning of the coater head was performed.

The increasing rate was challenging to control for the PBDTTTz-4 polymer because of its higher viscosity, and in the end, we were unable to perform the constant dry thickness experiment for the PBDTTTz-4 blends. The blends were all coated on the same substrate made of $30 \mathrm{~mm}$ wide and 125 $\mu \mathrm{m}$ thick polyethylene terephthalate (PET), cut into $30 \mathrm{~m}$ long strips which is limited by the coater rollers. Care was taken to ensure that the concentration coated onto the substrate was consistent with the pump rates, as the tubing going from the mixing unit to the coater head results in a delay in timing between changing the pumping rate, and when the resulting concentration reaches the coater head. This delay was calculated from the added volumes of coater head and tubes to be about 1 minute. The PET foil was kept tightly stretched using a brake on the unwinding roll which could be controlled to accommodate the changing diameter of the foil roll as the foil was used. Everything was performed in ambient atmosphere, with the temperature of the heating plate set to $60^{\circ} \mathrm{C}$ and $90^{\circ} \mathrm{C}$ respectively for P3HT and PBDTTTz-4. The coating speed, i.e. the speed of the moving foil, was constant at $0.5 \mathrm{~m} / \mathrm{min}$, the coating width also constant at $13 \mathrm{~mm}$ which results in dry layer thicknesses from $960 \mathrm{~nm}$ to $240 \mathrm{~nm}$ according to the changing concentrations.

Each experiment comprised a sequence of controlled actions. First, a syringe with the chosen solution was mounted on one syringe pump, and another syringe containing solvent mixture was mounted on the other. Then the pumps and rollers were started from outside the hutch, and after verifying that the coating was running smoothly, the X-ray beam was turned on and measurements begun. The measurement time of 1 minute was restricted by the time it took the coating head to move from furthest to closest to the beam. After the head movement, the rate of the syringe pumps was changed, and the same procedure repeated. For each mixture there were 4 concentrations as well as a cleaning run with pure solvent, which meant that for each of the mixtures P3HT, P3HT:PCBM, PBDTTTZ-4 and PBDTTTz-4:PCBM there were 5 runs, each of 60 seconds, or 656 measurements with a $10 \mathrm{~Hz}$ detector and accounting for read out time. The probed drying time was defined by the relative speed of the foil and the head, and the final distance between head and beam. The calculation in the Electronic Supplementary Information shows that with the foil speed of $500 \mathrm{~mm} / \mathrm{min}$, we can probe a drying time of 23 secs.

The wide and small angle measurements were performed at the cSAXS beamline at the Swiss Light Source. The grazing incidence alignment was done before performing the in situ measurements, using a standard sample of silver behenate to determine the sample-detector distance and by measuring the reflected beam position on the area detector. After alignment the incident angle was set to $0.35^{\circ}$ and kept constant for all the following measurements. The beam size $\left(w^{*} h\right)$ was 100 $\mu \mathrm{m} * 50 \mu \mathrm{m}$, with an X-ray energy of $13.6 \mathrm{keV}$, which gives a wavelength $(\lambda)$ of $0.912 \AA$. We did measurements at two sample-detector distances, for small angles the distance was $2.2 \mathrm{~m}$ and for wide angles it was $0.629 \mathrm{~m}$. The detector was a Pilatus $2 \mathrm{M}$ with a resolution of $1679 \times 1475$ pixels and a pixel size of $173 \mu \mathrm{m} \times 173 \mu \mathrm{m}^{24}$. The wide-angle scattering measurements were analysed by making radial and azimuthal integrations. Three parameters are extracted by doing Gaussian fits to the structure peaks of the polymers in the radially integrated curves: The position of the peak in $q(|q|=$ $4^{*} \mathrm{pi}^{*} \sin \theta / \lambda$, where $2 \theta$ is the scattering angle) gives the packing separation of the polymers out of the plane via the equation $d=2 *$ pi/q. The width of the peak is a relative measure of the size of semi-crystalline domains in the polymer, cf. the Scherrer equation ${ }^{25,26}$; and the area of the peaks represent the integrated intensity collected in that specific peak which is related to crystallinity. The result is a 4part plot for each dataset which shows the three parameters as a function of the same time axis allowing direct comparison between their changes, together with a measure of the structure of the polymer.

\section{Polymers}

The two polymers that were used in this study were $\mathrm{P} 3 \mathrm{HT}$ and PBDTTTZ-4. The PBDTTTz-4 polymer was developed specifically for R2R coating ${ }^{11,10}$, and among its main features is a larger sidechain structure which leads to increased viscosity, and a stronger tendency to form agglomerates in solution ${ }^{10}$. A higher temperature compared to $\mathrm{P} 3 \mathrm{HT}$ is therefore needed when coating the polymer $\left(90^{\circ} \mathrm{C}\right)^{27}$. The higher viscosity is favourable for $R 2 R$ coating because the coated film is more resistant to mechanical instabilities such as movement of the substrate.

The 98\% regioregular Poly(3-hexyl)thiophene (P3HT) was obtained from BASF, Sepiolid P200; and (6,6)-phenyl-C61butyric acid methyl ester (PCBM) from Solenne BV. To achieve the highest comparability between the two systems the same solvent mixture was used for both polymer mixtures in the ratios 87:10:3 of chlorobenzene:chloroform:chloronaphtalene, all solvents acquired from Sigma Aldrich, and of analytical grade.

\section{Conclusions}

The results presented here show that a polymer suited for $R 2 R$ coating should have a drying development with little dependence on the specific drying conditions. The polymer optimized for R2R coating investigated here attains its final packing distance instantly after deposition, and has drying profiles with little dependence on concentration. We call the polymer characteristics leading to good R2R coating a robust polymer. The exact prescription for such a polymer is still somewhat uncertain. For some polymers, such as PffBT4T2OD, aggregation in solution can be controlled, but only at prohibitively high temperatures for R2R processing ${ }^{28}$, whereas a polymer such as PTB7, in our experience does not perform 
well in the relatively thick active layers prepared by slot-die coating. By a combination of material characteristics, PBDTTTz4 happens to fulfil all requirements for the R2R processing. We expect that fused thiophenes providing the polymer with a rigid backbone facilitates ordering in solution. And, contrary to P3HT, the fixed regioregularity of PBDTTTz-4 helps reducing the batch to batch variability of the polymer, yielding predictable and consistent results in large area device fabrication. The interplay between side-chain modifications and drying kinetics, solvent and structure is still poorly understood, however. The same polymer, with larger sidechain structures were shown, as part of a large matrix screening study, to perform worse than P3HT in R2R coated devices (polymer A6D9 in Bundgaard et al. $^{12}$ ).

Crystallinity appeared inconsequential for the performance of the R2R coated polymer, illustrated by our observation that the R2R-optimized polymer was much less crystalline. The results also show that the polymer structure is mainly defined by drying kinetics, which is expected because the drying polymer is in an equilibrium state in the case of R2R coating. This is in contrast with the other much used processing technique, spin coating, where the polymer is quenched into its final state by the fast removal of material and solvent. From these considerations, we therefore propose that the wettability combined with optimal viscosity and solvent mixture is more important than crystallinity for the performance in this case. All the conclusions thus support the better performance of PBDTTTz-4 compared to P3HT in R2R coated devices. The challenges of the measurements highlighted some of the possible improvements to in situ experiments, such as simultaneous small and wide angle measurements and high quality video feeds. With these additions, the already impressive statistical significance of this type of results would be further improved.

\section{Conflicts of interest}

There are no conflicts to declare.

\section{Acknowledgements}

This work was supported by the Danish Ministry of Science, Innovation and Higher Education under a Sapere Aude Top Scientist grant (no. DFF - 1335-00037A) an Elite Scientist grant (no. 11-116028) and through the instrumentation centre grant DANSCATT - 7055-00001B. IR acknowledges support from the European Union Seventh Framework Programme (FP7/20072013) under grant agreement n. ${ }^{\circ} 290605$ (PSIFELLOW/COFUND). JWA acknowledges support by the H2020 European Research Council through the SEEWHI Consolidator grant, ERC-2015-CoG-681881.

\section{Notes and references}

1. Søndergaard, R., Hösel, M., Angmo, D., Larsen-Olsen, T. T. \& Krebs, F. C. Roll-to-roll fabrication of polymer solar cells.
Materials Today 15, 36-49 (2012).

2. Yu, G. \& Heeger, A. J. Charge separation and photovoltaic conversion in polymer composites with internal donor/acceptor heterojunctions. J. Appl. Phys. 78, 45104515 (1995).

3. Liu, F., Gu, Y., Jung, J. W., Jo, W. H. \& Russell, T. P. On the morphology of polymer-based photovoltaics. J. Polym. Sci. Part B Polym. Phys. 50, 1018-1044 (2012).

4. Ruderer, M. A. \& Müller-Buschbaum, P. Morphology of polymer-based bulk heterojunction films for organic photovoltaics. Soft Matter 7, 5482 (2011).

5. Pröller, S. et al. Following the Morphology Formation In Situ in Printed Active Layers for Organic Solar Cells. Adv. Energy Mater. 6, 1501580 (2016).

6. Böttiger, A. P. L., Jørgensen, M., Menzel, A., Krebs, F. C. \& Andreasen, J. W. High-throughput roll-to-roll X-ray characterization of polymer solar cell active layers. J. Mater. Chem. 22, 22501-22509 (2012).

7. Hösel, M., Søndergaard, R. R., Jørgensen, M. \& Krebs, F. C. Fast Inline Roll-to-Roll Printing for Indium-Tin-Oxide-Free Polymer Solar Cells Using Automatic Registration. Energy Technol. 1, 102-107 (2013).

8. Krebs, F. C., Gevorgyan, S. A. \& Alstrup, J. A roll-to-roll process to flexible polymer solar cells: model studies, manufacture and operational stability studies. J. Mater. Chem. 19, 5442-5451 (2009).

9. Gu, X. et al. Compact Roll-to-Roll Coater for in Situ X-ray Diffraction Characterization of Organic Electronics Printing. ACS Appl. Mater. Interfaces 8, 1687-94 (2016).

10. Carlé, J. E., Helgesen, M., Madsen, M. V., Bundgaard, E. \& Krebs, F. C. Upscaling from single cells to modules fabrication of vacuum- and ITO-free polymer solar cells on flexible substrates with long lifetime. J. Mater. Chem. C 2, 1290-1297 (2014).

11. Helgesen, M. et al. Making ends meet: Flow synthesis as the answer to reproducible high-performance conjugated polymers on the scale that roll-to-roll processing demands. Adv. Energy Mater. 5, 1-7 (2015).

12. Bundgaard, E. et al. Matrix Organization and Merit Factor Evaluation as a Method to Address the Challenge of Finding a Polymer Material for Roll Coated Polymer Solar Cells. Adv. Energy Mater. 5, 1402186 (2015).

13. Brabec, C. J. et al. Polymer-Fullerene Bulk-Heterojunction Solar Cells. Adv. Mater. 22, 3839-3856 (2010).

14. Alstrup, J., Jørgensen, M., Medford, A. J. \& Krebs, F. C. Ultra fast and parsimonious materials screening for polymer solar cells using differentially pumped slot-die coating. ACS Appl. Mater. Interfaces 2, 2819-27 (2010).

15. Moseguí González, D. et al. Codependence between Crystalline and Photovoltage Evolutions in P3HT:PCBM Solar Cells Probed with in-Operando GIWAXS. ACS Appl. Mater. Interfaces 9, 3282-3287 (2017).

16. Sirringhaus, H. et al. Mobility enhancement in conjugated polymer field-effect transistors through chain alignment in a liquid-crystalline phase. http://oasc12039.247realmedia.com/RealMedia/ads/click Ix.ads/www.aip.org/pt/adcenter/pdfcover_test/L- 
37/1766726050/x01/AIP-

PT/APL_ArticleDL_090617/CiSE_Fingertips_1640x440.jpg/4 34f71374e315a556e61414141774c75?x (2000).

doi:10.1063/1.126991

17. Bae, Y.-J., Yang, H.-J., Shin, S.-H., Jeong, K.-U. \& Lee, M.-H. A novel thin film polarizer from photocurable non-aqueous lyotropic chromonic liquid crystal solutions. J. Mater.

Chem. 21, 2074 (2011).

18. Kleinhenz, N. et al. Liquid Crystalline Poly(3-

hexylthiophene) Solutions Revisited: Role of TimeDependent Self-Assembly. Chem. Mater. 27, 2687-2694

(2015).

19. Kleinhenz, N. et al. Ordering of Poly(3-hexylthiophene) in Solutions and Films: Effects of Fiber Length and Grain Boundaries on Anisotropy and Mobility. Chem. Mater. 28, 3905-3913 (2016).

20. Qu, G., Kwok, J. J. \& Diao, Y. Flow-Directed Crystallization for Printed Electronics. Acc. Chem. Res. 49, 2756-2764 (2016).

21. Yoneda, Y. Anomalous surface reflection of $\mathrm{X}$ rays. Phys. Rev. 131, 2010-2013 (1963).

22. Rossander, L. H., Zawacka, N. K., Dam, H. F., Krebs, F. C. \& Andreasen, J. W. In situ monitoring of structure formation in the active layer of polymer solar cells during roll-to-roll coating. AIP Adv. 4, 87105 (2014).

23. Dam, H. F. \& Krebs, F. C. Simple roll coater with variable coating and temperature control for printed polymer solar cells. Sol. Energy Mater. Sol. Cells 97, 191-196 (2012).

24. Henrich, B. et al. PILATUS: A single photon counting pixel detector for X-ray applications. Nucl. Instruments Methods Phys. Res. Sect. A Accel. Spectrometers, Detect. Assoc. Equip. 607, 247-249 (2009).

25. Scherrer, P. Bestimmung der Größe und der inneren Struktur von Kolloidteilchen mittels Röntgenstrahlen. Nachrichten von der Gesellschaft der Wissenschaften zu Göttingen, Math. Klasse 1918, 98-100 (1918).

26. Langford, J. I. \& Wilson, A. J. C. Scherrer after sixty years: A survey and some new results in the determination of crystallite size. Journal of Applied Crystallography 11, 102113 (1978).

27. Helgesen, M., Carle, J. E. \& Krebs, F. C. Slot-die coating of a high performance copolymer in a readily scalable roll process for polymer solar cells. Adv. Energy Mater. 3, 1664-1669 (2013).

28. Liu, Y. et al. Aggregation and morphology control enables multiple cases of high-efficiency polymer solar cells. Nat. Commun. 5, 5293 (2014). 
Polymer conformation in solution is more important for R2R solar cell performance, than the crystallinity of the final coated film. 


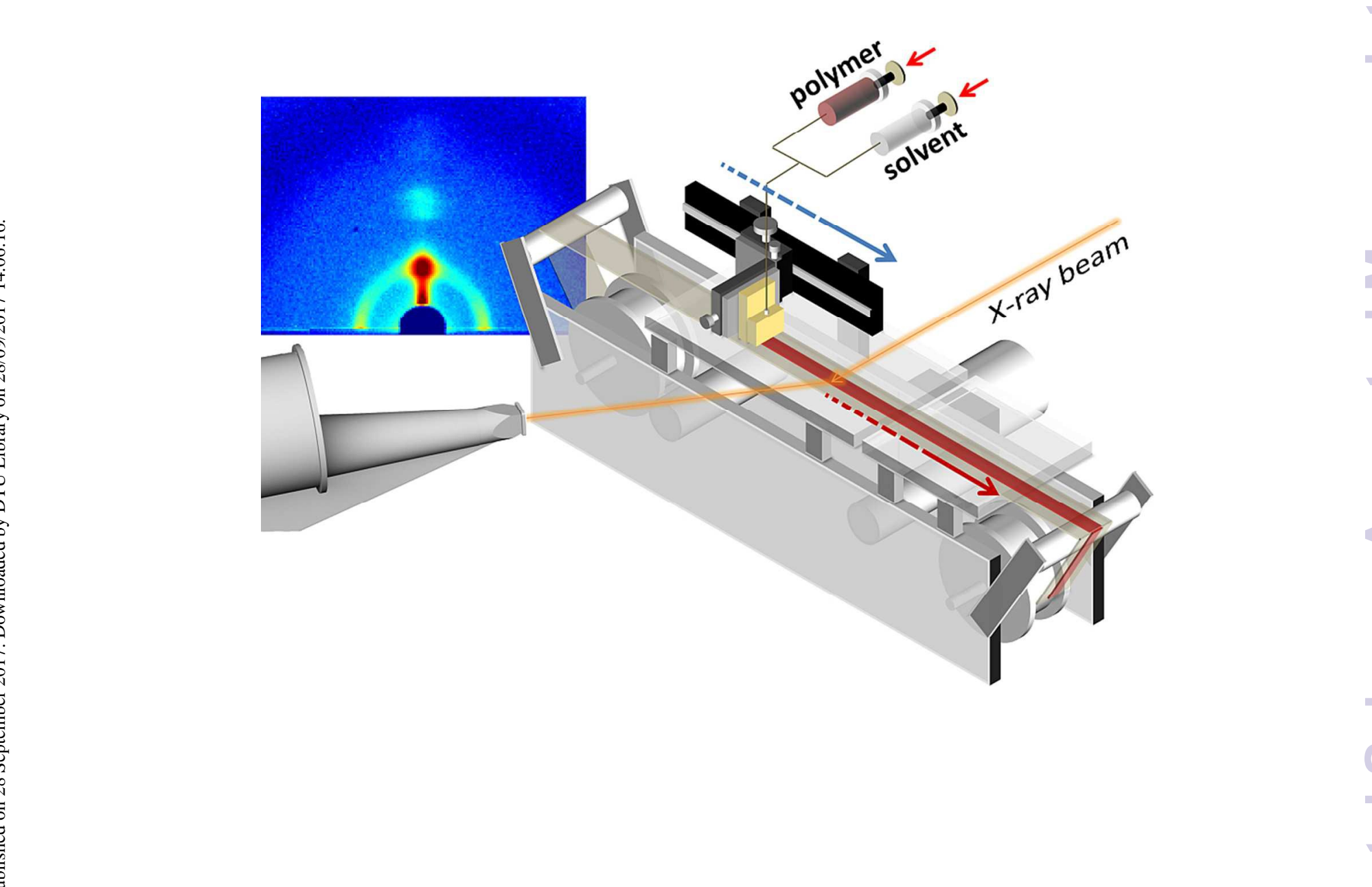




\section{Broader Context}

We present in situ X-ray scattering studies of scalable polymer solar cell manufacture, recorded under conditions that are fully compatible with real industrial processing. The experiments are not limited to small scales, but cover tens of meters coating at high speed. This is the first demonstration that fast, in situ X-ray scattering can be used to cover a large parameter space by combination with differential pump slotdie coating, used for a comprehensive comparison of two polymers currently used in large scale manufacturing of polymer solar cells. We conclude that the polymer conformation and behavior in solution is more important for the performance of roll-to-roll coated devices, than the crystallinity of the final coated film. This is a novel and surprising observation, that goes a long way in explaining the apparent mismatch between polymers that perform well in small spin-coated devices, yielding poor performance in large roll-to-roll coated devices and vice versa. This is important for the entire community interested in upscaling of energy devices relying on structure and morphology of materials in thin films. We foresee that in situ X-ray scattering may become an indispensable tool for optimization of devices in a scalable setting, not just polymer solar cells. 